\title{
EXPERIMENTAL STUDY OF DAMAGED CR-COATED FUEL CLADDING IN POST-ACCIDENT CONDITIONS
}

\author{
Petr Červenka ${ }^{a, b, *}$, Jakub KrejČí ${ }^{b}$, Ladislav CvrČEK $^{a}$, \\ VOJTĚCH ROZKOŠnÝ ${ }^{b}$, FrANTIŠEK MANOCH $^{b}$, DAVID RADA ${ }^{b}$, \\ JiTKA KABÁTOVÁ ${ }^{b}$ \\ ${ }^{a}$ Czech Technical University in Prague, Faculty of Mechanical Engineering, Department of Material Engineering, \\ Karlovo náměsti 293/13, Prague, 12000, Czech Republic \\ ${ }^{b}$ UJP PRAHA a.s., Nad Kaminkou 1345, Praha-Zbraslav, 15610, Czech Republic \\ * corresponding author: cervenka@ujp.cz
}

\begin{abstract}
To enhance the safety of nuclear power, the focus of researchers all around the world has recently mainly objected on the development of Accident Tolerant Fuels. Especially the Chromium coating of current Zirconium based cladding has been widely suggested and discussed for its immense positive effect on overall cladding properties. Nevertheless, it was observed that during the first stage of the Loss of Coolant Accident, cracks appear in the Cr coating due to its inability to tolerate higher plastic strain. Therefore, experimental methodology used in this article focuses on testing fuel cladding with damaged $\mathrm{Cr}$ coating after the high-temperature transient. The impact of cracks on degradation of cladding mechanical properties was observed using optical microscopy, ring compression test, microhardness, and evaluating hydrogen content and weight gain.
\end{abstract}

KEYwORDS: ATF, cladding embrittlement, coating, LOCA, oxidation.

\section{INTRODUCTION}

Over the years, many concepts of Accident Tolerant Fuels (ATFs) have been suggested [1]. The main objective of ATF is to mitigate the possible negative consequences occurring in accident conditions. This article deals with the design basis accident (DBA), namely, the Large Break Loss of Coolant Accident (LB-LOCA). During the LB-LOCA, the peak cladding temperature (PCT) might reach $1200{ }^{\circ} \mathrm{C}$. The process of oxidation is accelerated at temperatures over $800{ }^{\circ} \mathrm{C}$ which is also a temperature when zirconium undergoes a phase transformation from its $\alpha$ phase to the $\beta$ phase. The oxide dissolved in metal stabilizes the $\alpha$ phase which grows at the expense of the $\beta$ phase. Part of oxygen then dissolves in the $\beta$ phase. If the amount of oxygen absorbed is too high, the cladding becomes brittle. Since the structural integrity is essential, the load-bearing prior $\beta$ phase must be thick enough to withstand various stresses occurring in and after the quench phase of LB-LOCA, otherwise, it might end up in a rupture of the cladding.

The most promising ATF concept is the fuel cladding made of Zr-based alloy with a protective Cr coating of outer wall [2, 3. Coating slows down the absorption rate of hydrogen as well as the process of oxidation in normal operation [4 6]. Moreover, calculations show that a thin layer of $\mathrm{Cr}$ entails only a minor decrease in a fuel cycle length [7]. Regarding the accident conditions, the positive impact of $\mathrm{Cr}$ coating has been presented. Reduced deformation leading to a decelerated ballooning process as well as prolongation of time to burst was observed 8 .
The crucial hypothesis is that in the first stage of the LOCA accident, in the process of ballooning, cracks appear in the protective chromium layer due to its inability to tolerate higher plastic strain. Therefore, the cladding is locally not being protected from the accelerated oxidation process when high temperatures are reached. This contribution focuses on evaluating the effect of cracks on the overall mechanical properties of fuel cladding after the high-temperature transient.

\section{Methods}

\subsection{Preparation of Specimens}

All experiments were performed using non-irradiated $\mathrm{Zr}-1 \% \mathrm{Nb}$ (E110) alloy, which is the main cladding material used in Water-cooled water-moderated power reactors (WWERs). It was observed that the negative effects of irradiation are annealed when the temperature is rising and the material recovers before reaching $\mathrm{PCT}$, therefore testing of non-irradiated cladding is possible 9, 10. The geometry of tested specimens:

- length $45 \mathrm{~mm}$

- outer diameter (OD) $9.1 \mathrm{~mm}$

- inner diameter (ID) $7.93 \mathrm{~mm}$

- wall thickness $\sim 0.6 \mathrm{~mm}$

Specimens were divided into three branches: reference cladding, Cr coated cladding, and damaged $\mathrm{Cr}$ cladding.

First, the specimens were ultrasonically cleaned in acetone, ethanol, and distilled water (in that order). Then, a chromium layer was deposited on the outer 


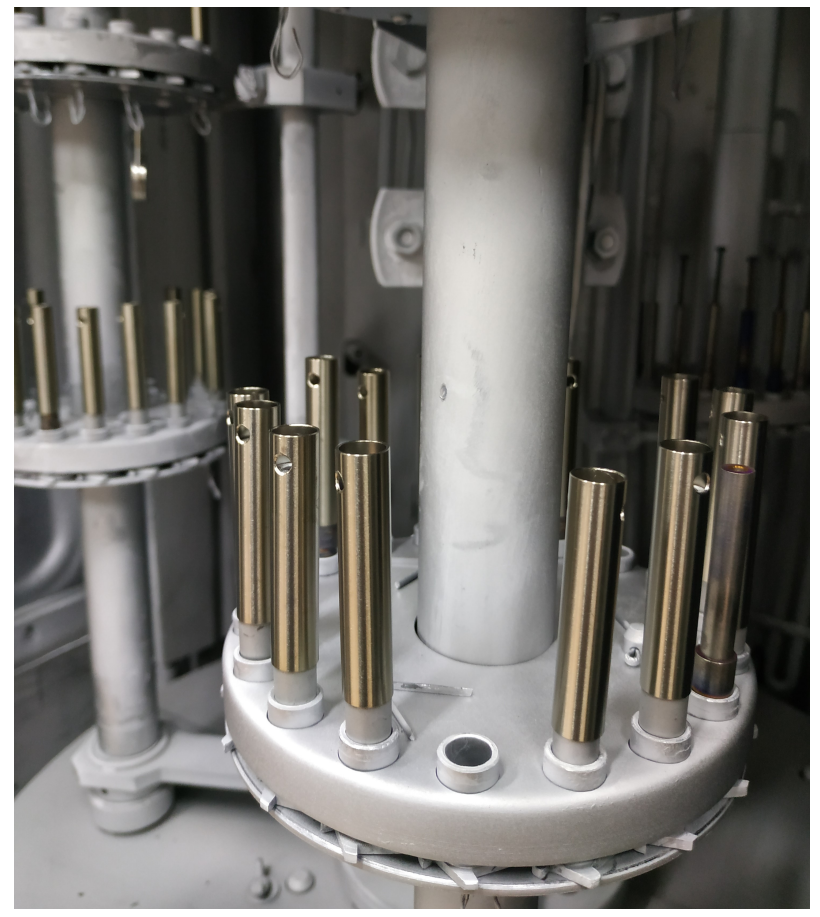

Figure 1. The chamber of Hauzer Flexicoat 850 system.

surface of the specimen using the magnetron sputtering process with $99.6 \%$ Cr sputtering targets in the protective argon atmosphere of the Hauzer Flexicoat 850 device (Figure 1). The process lasted 16 hours at the temperature of $250{ }^{\circ} \mathrm{C}$, which is even lower than the normal operation cladding temperature in the core, thus the cladding was not thermally affected. Finally, the coating thickness of $18.6 \mu \mathrm{m}$ was determined using the calotest method (Figure 3). To simulate the coating defects (cracks) occuring during the ballooning process, several scratches through the chromium layer were made using the scratch test device CSM Instruments Revetest Xpress (Figure 2). The constant force of $50 \mathrm{~N}$ was required to make the scratch go through the whole chromium layer without affecting the $\mathrm{Zr}$ substrate more than necessary by adding additional local plastic deformation. The resulting U-shaped scratches (Figures 6, 7) had a width of $200 \mu \mathrm{m}$ and the length of $40 \mathrm{~mm}$.

\subsection{High-Temperature Oxidation}

The process of ballooning might result in the burst of cladding, hence the the double-sided high-temperature oxidation experiments were performed as it is more conservative approach. The Cr-coated outer surface is expected to be protected from oxidation, whereas the oxygen is supposed to be absorbed through the inner wall. In addition to that, such experiments might clearly show the difference in oxidation rate through the whole (inner) surface and locally through the scratched (damaged) coating.

The experiment of high-temperature oxidation was performed in an electric resistance furnace (Figure 4)

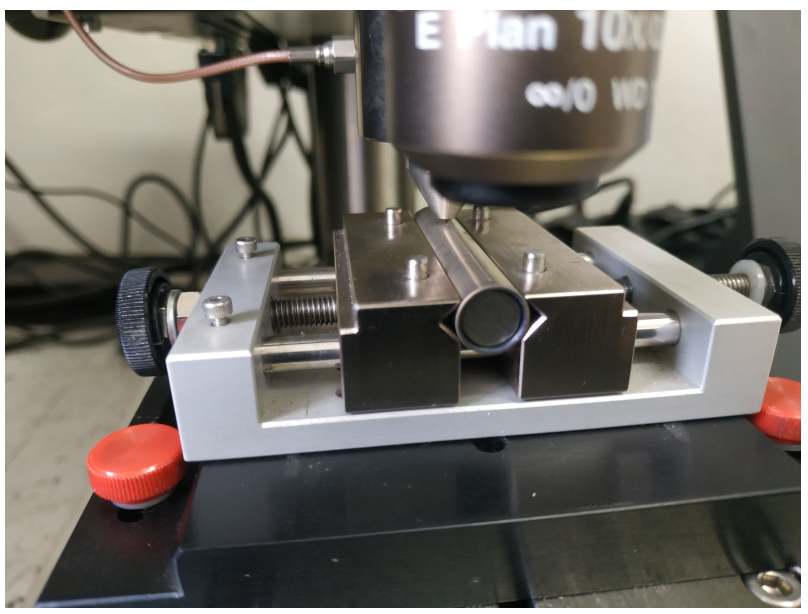

Figure 2. Process of creating scratches.

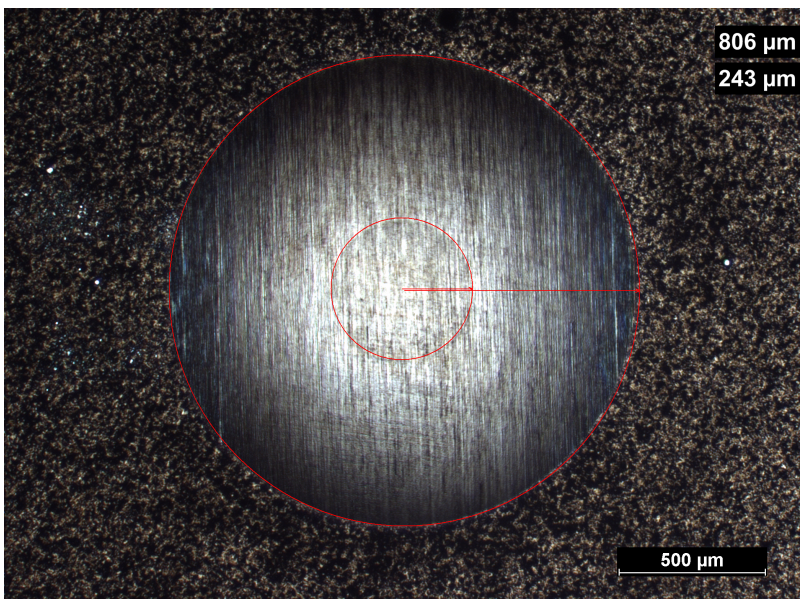

Figure 3. Calotest

in an argon-steam mixture according to the scheme shown in Figure 5 The temperature of the experiment was set up to $1200 \pm 3^{\circ} \mathrm{C}$ since it is generally accepted as the highest possible temperature within the acceptance criteria for DBAs [2]. A thermocouple was located inside the cladding tube and it was recording the temperature every 2 seconds. Specimens were oxidized for $1.5 ; 3 ; 4.5$ and 9 minutes. At the end of the experiment, the specimens were directly quenched in cold water (water + ice) and dried out at the temperature of $90{ }^{\circ} \mathrm{C}$.

\subsection{WEIGHT-GAIN}

The non-destructive testing of oxidized samples was performed on Mettler Toledo XS 105 semi-micro balance with the readability of $0,01 \mathrm{mg}$. Specimens were weighed both before and after the high-temperature oxidation, thus the experimental value of weight gain WG-exp $\left[\mathrm{mg} / \mathrm{dm}^{2}\right]$ could have been calculated. In addition to that, the estimated value of weight gain WG-CP $\left[\mathrm{mg} / \mathrm{dm}^{2}\right]$ was calculated using the experimental temperatures and the Cathcart-Pawel correlation. After the process of weighing, the specimens were cut into smaller rings for the purposes of destructive testing. Using Buehler IsoMet 5000 linear precision 


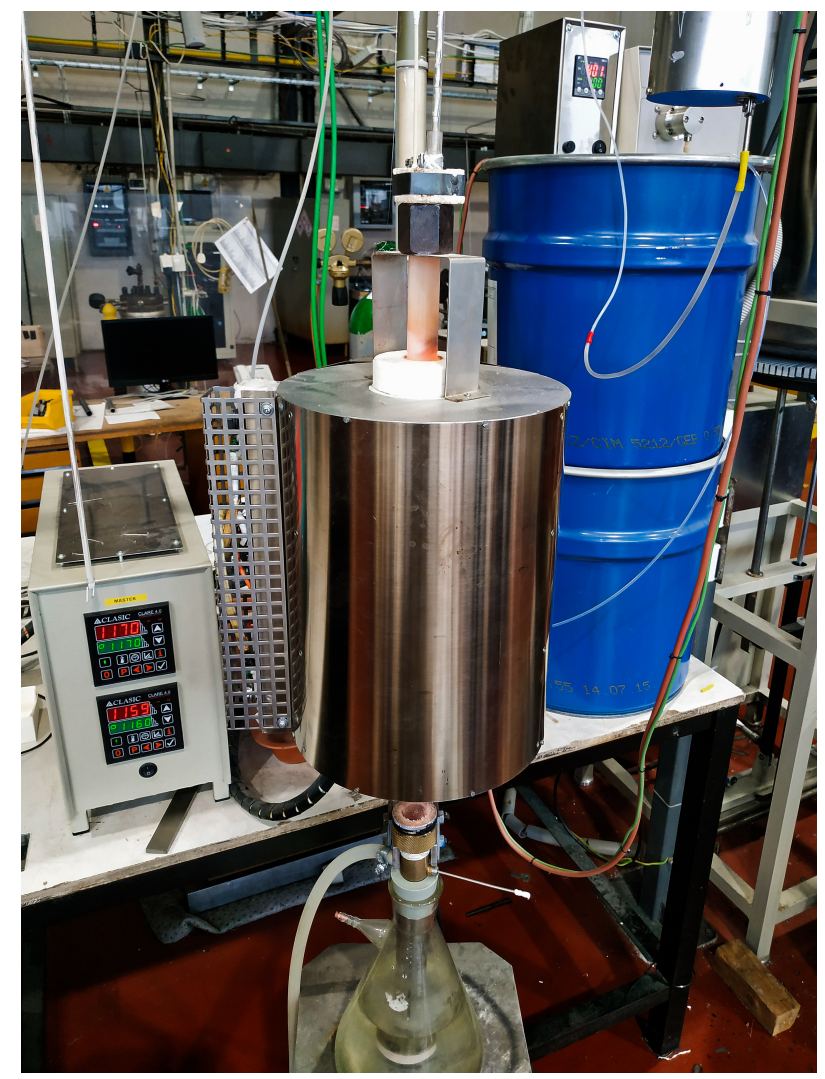

FIgURE 4. The apparatus for high-temperature oxidation.

saw rings of the following lengths were cut:

- $1.5 \mathrm{~mm}$ - hydrogen content analysis

- $7 \mathrm{~mm}$ - optical microscopy, microhardness

- $4 \times 7 \mathrm{~mm}-$ ring compression test

\subsection{Ring Compression Test}

To evaluate the residual ductility, a ring compression test (RCT) was performed on Instron 1185 machine. For the purposes of this test, small rings of a width of $7 \mathrm{~mm}$ were cut from the oxidized specimens. Those rings were pressed at a constant speed of $1 \mathrm{~mm} / \mathrm{min}$. The temperature of the experiment was $135 \pm 1{ }^{\circ} \mathrm{C}$. The ductile enough specimens oxidized for 1.5 minutes were not a subject of this test. The compression was stopped if the displacement of $2 \mathrm{~mm}$ was reached since the measured ductility was not relevant to determine the ductile-brittle transition area.

\subsection{Hydrogen Content}

The analysis of hydrogen content was performed on G8 Galileo Brucker machine by using the Inert Gas Fusion (IGF) method. Short rings of a width of 1.5 $\mathrm{mm}$ were cut from the oxidized specimen. Afterward, those rings were fused in a vacuum atmosphere at the temperature of $1300^{\circ} \mathrm{C}$. Together with other gases, hydrogen was extracted from the fused specimen and carried by an inert gas. The evaluation of hydrogen content is based on the differences of the measured thermal conductivity of evolved gases.

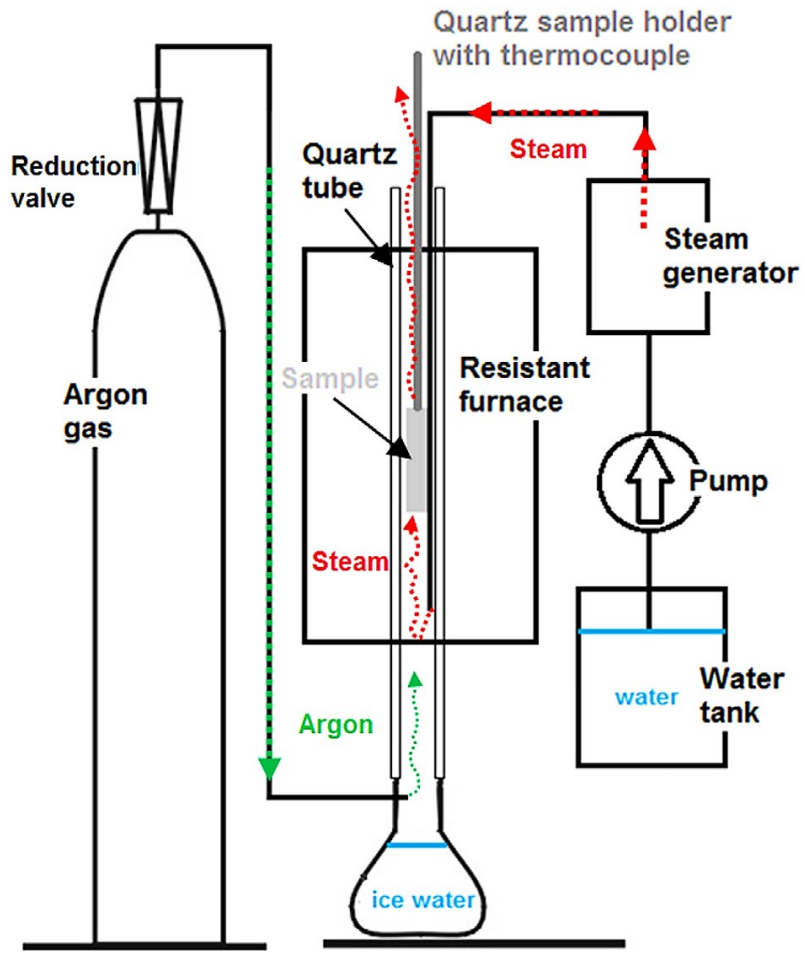

FiguRE 5. The scheme of high-temperature oxidation experiment.

\subsection{Optical Metallography}

Metallographic specimens were analyzed using an optical microscope Nicon Eclipse MA200. The images were captured and enhanced using NIS-Elements software. In the Figure 6 a typical microstructure of high temperature oxidized specimen can be seen. The oxygen-stabilized $\alpha-\operatorname{Zr}(\mathrm{O})$ phase grows from the unprotected surface at the expense of load-bearing prior $\beta$-Zr phase. In addition to that, the process of oxygen absorption through the coating defects (scratches) locally leading to the growth of the $\alpha-\operatorname{Zr}(\mathrm{O})$ phase can be seen, whereas there is no oxidation through the undamaged coating (Figure 6). Since the E110 tested cladding contains $\mathrm{Nb}$, there is a layer of both $\alpha-\mathrm{Zr}(\mathrm{O})$ and $\beta-\mathrm{Zr}$ grains. The structure of $\mathrm{Zr}$ cladding without Nb (such as Zry-4) is shown in Figure 6, the difference in the presence of the layer containing both $\alpha-\mathrm{Zr}(\mathrm{O})$ and $\beta-\mathrm{Zr}$ grains is evident. The local microstructure close to the scratch is very similar to the microstructure in the area of the inner surface.

\subsection{MiCROHARDNESS}

The hardness across the cladding wall was analyzed on Buehler Micromet 5114 device by using the Vickers microhardness test. The pyramidal Vickers-type indenter was used and the test load was $0,1 \mathrm{~kg}$. On each specimen, 10 square indents were produced in 5 lines across the cladding wall as shown in Figure 7 Afterward, every indent was precisely located using GetData Graph Digitizer software to get the information about the position and appropriate hardness. As a result, the hardness profiles across the wall in 

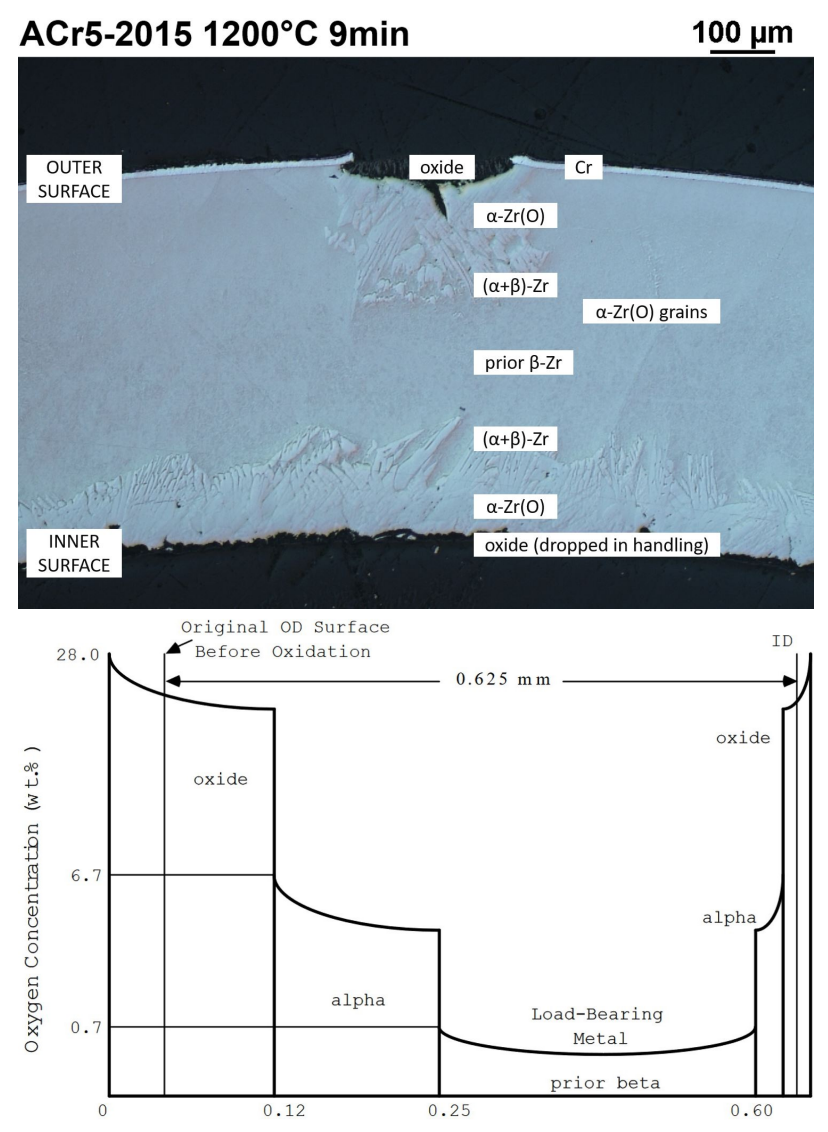

Distance from OD Oxide Surface

Figure 6. Typical misrostructure of high-temperature oxidized Zr-based cladding: with $\mathrm{Nb}$ (top) and without $\mathrm{Nb}$ (bottom).

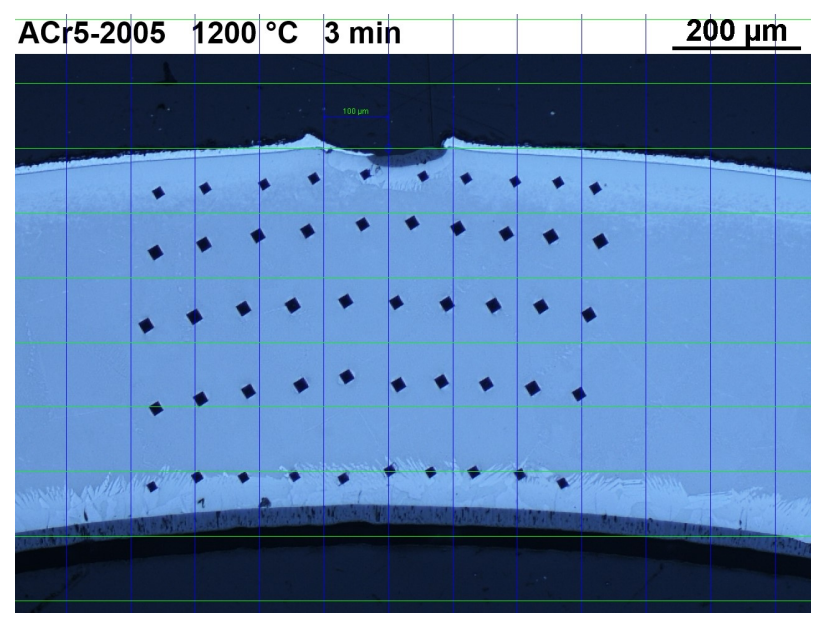

FiguRE 7. Microhardness indents in 5 vertical lines.

both longitudinal and transverse directions as well as surface maps of hardness were generated.

\section{Results}

\subsection{WEIGHT-GAIN}

As it can be seen in Figure 8, the coating effectively protects the cladding from oxidation. Even in the case of a 9-minute exposition, the weight gain is relatively small. On the contrary, the reference cladding oxi-

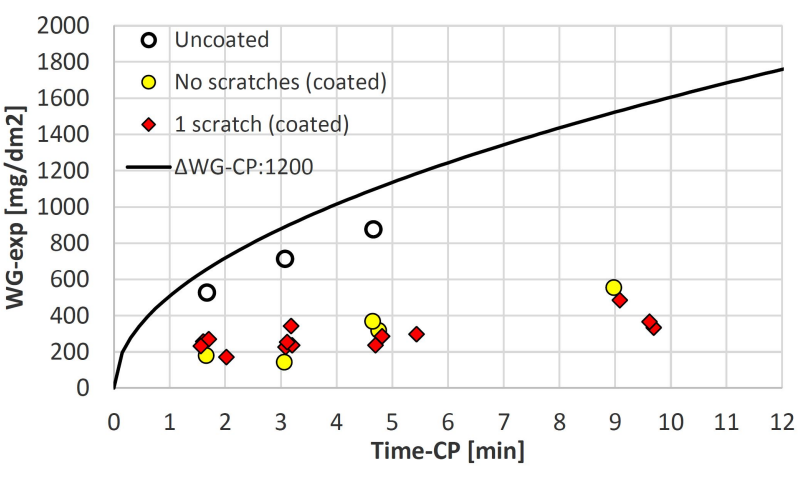

Figure 8. Results of weight-gain.

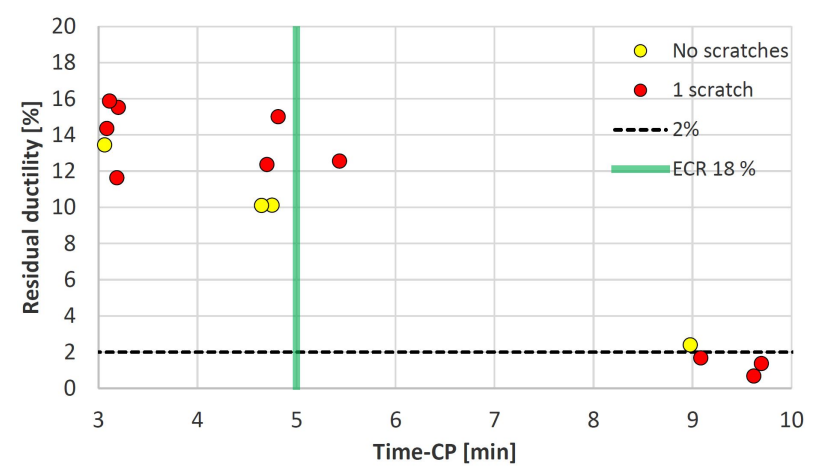

Figure 9. Results of RCT with theoretically obtained value (green) for double-sided oxidation (=uncoated).

dized from both sides features a significantly higher weight gain, which is rather similar to the expected rate calculated according to the Cathcart-Pawel correlation [11. Furthermore, Figure 8 shows the weight gain comparison of the coated cladding with and without a scratch (red and yellow dots). The presence of scratch did not have a measurable impact on the overall weight gain.

\subsection{Ring Compression Test}

The residual ductility of $2 \%$ is generally considered as the ductile-brittle transition. All specimens seem to undergo the transition at the time of high-temperature oxidation lasting around 9 minutes. The presence of the scratch does not seem to affect the ductile-brittle transition as shown in the Figure 9 According to the Cathcart-Pawel correlation (Equivalent Cladding Reacted - ECR-CP $18 \%$ ), the limit time value of hightemperature oxidation at $1200^{\circ} \mathrm{C}$ for double-sided oxidation is 5 minutes. Therefore, regardless of the scratch being present or not, the coated specimens feature a significantly longer time to undergo the ductile-brittle transition, thus the positive impact of Cr coating is apparent.

As all specimens had inclined to crack on the side, specimens with scratches were tested twice to determine the impact of the crack rotation. First, the cladding ring was rotated featuring a scratch on the top, second, the scratch was on the side. The results are summarized in Figure 10. 


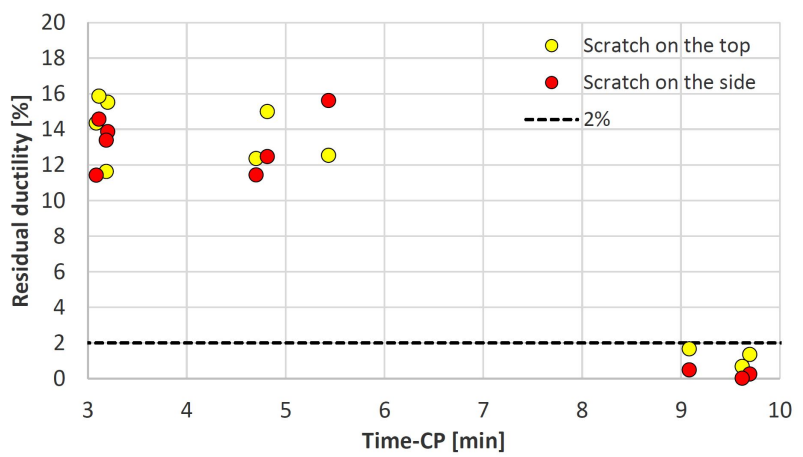

Figure 10. Comparison of differently rotated scratches.

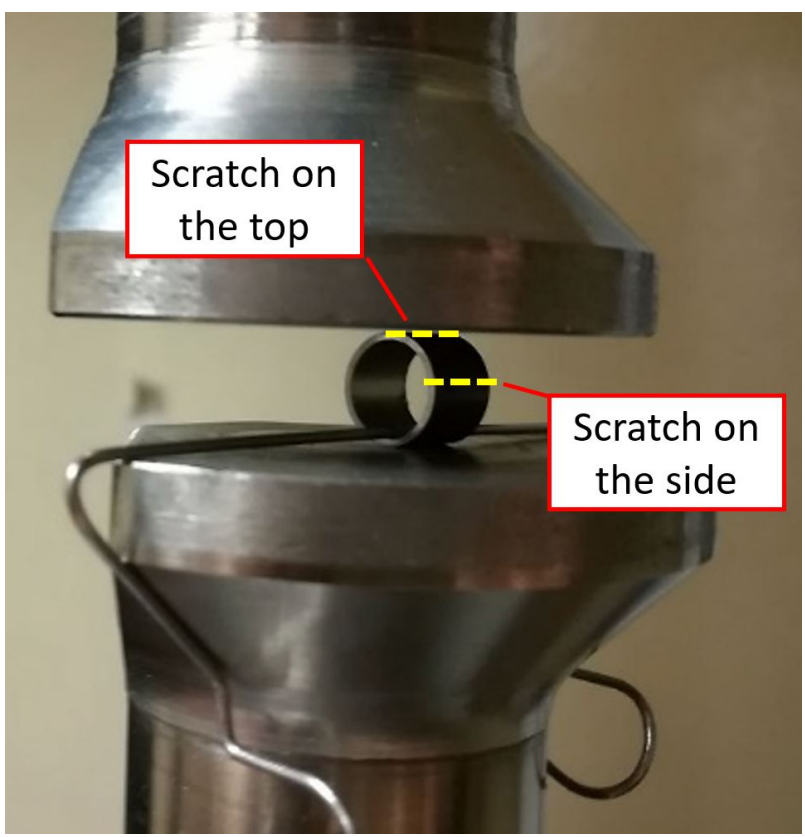

Figure 11. Ring Compression Test with the position of the scratch.

\subsection{Hydrogen Content}

The hydrogen pickup is lower than $50 \mathrm{ppm}$ for all specimens. Regardless of the presence of the scratch, the coating protects the cladding from accelerated hydrogen pickup. According to current knowledge, there is no impact of low hydrogen concentration $(<$ $70 \mathrm{ppm}$ ) on cladding ductility [12], therefore hydrogen pickup cannot be the reason behind the tested cladding embrittlement.

\subsection{MiCROHARDNESS}

The hardness increases sharply with the phase transition. The ductile load-bearing prior $\beta$ - Zr is characterized by the hardness of $<300 \mathrm{HV} 0,1$, whereas the $\alpha-\mathrm{Zr}(\mathrm{O})$ typically shows the hardness of $450-600 \mathrm{HV}$ 0,1 . As the solubility of oxygen in $\beta-\mathrm{Zr}$ is limited, by extending the time of high-temperature oxidation, the deceleration of increasing hardness rate is observed (Figure 12). Once the values of around $350 \mathrm{HV} 0,1$ are reached, the amount of oxygen possibly dissolved in $\beta-\mathrm{Zr}$ is close to its limit. Accordingly, by prolonging the time of the high-temperature oxidation, HV0,1

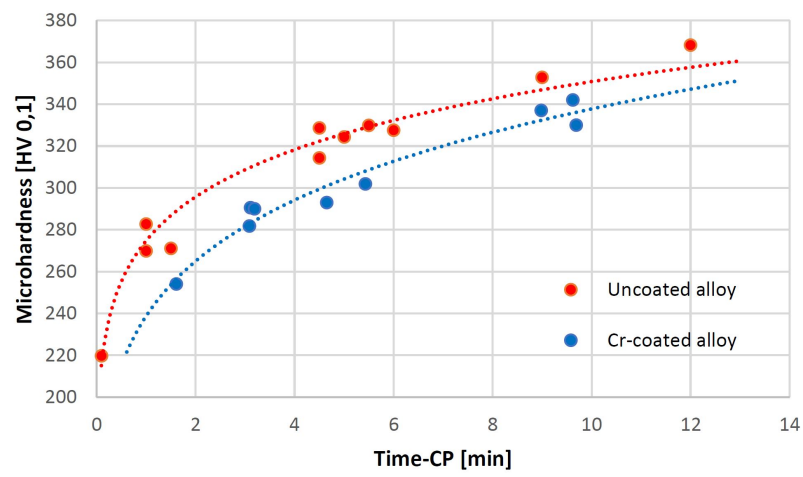

Figure 12. Comparison of single- and double-sided oxidation.

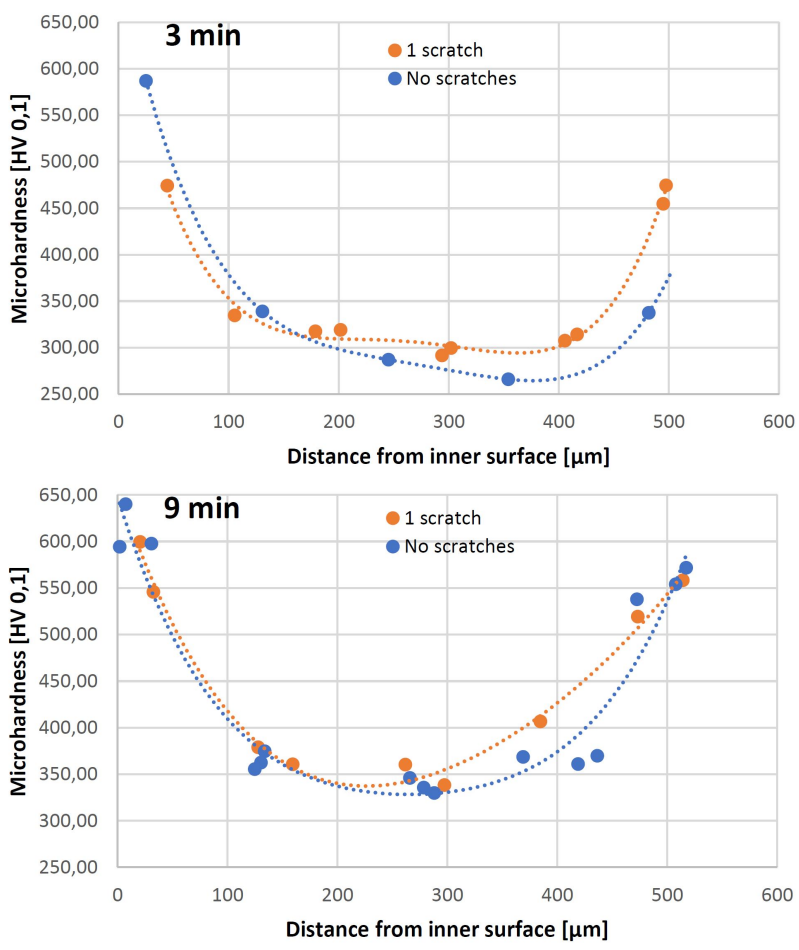

FIgURE 13. Transversely measured microhardness: 3 min exposition (top) and 9 min exposition (bottom).

values remain nearly steady until the sharp increase of hardness values is measured due to the growth of very hard $\alpha-\operatorname{Zr}(\mathrm{O})$ grains.

The increase in the hardness values at the area near the uncoated surface is the result of oxygen absorption. Against the odds, the hardness values increase also close to the coated surface as shown in Figure 13 The diffusion of $\mathrm{Cr}$ coating into the $\mathrm{Zr}$ substrate is clearly present. The longer is the time of the hightemperature oxidation, the larger is the affected area with increased values of hardness. The results in the form of surface plots are presented in Figure 14.

\section{Discussion}

The study of mechanical properties of damaged coated cladding in post-accident conditions is still unique and similar results have not been widely observed yet. 


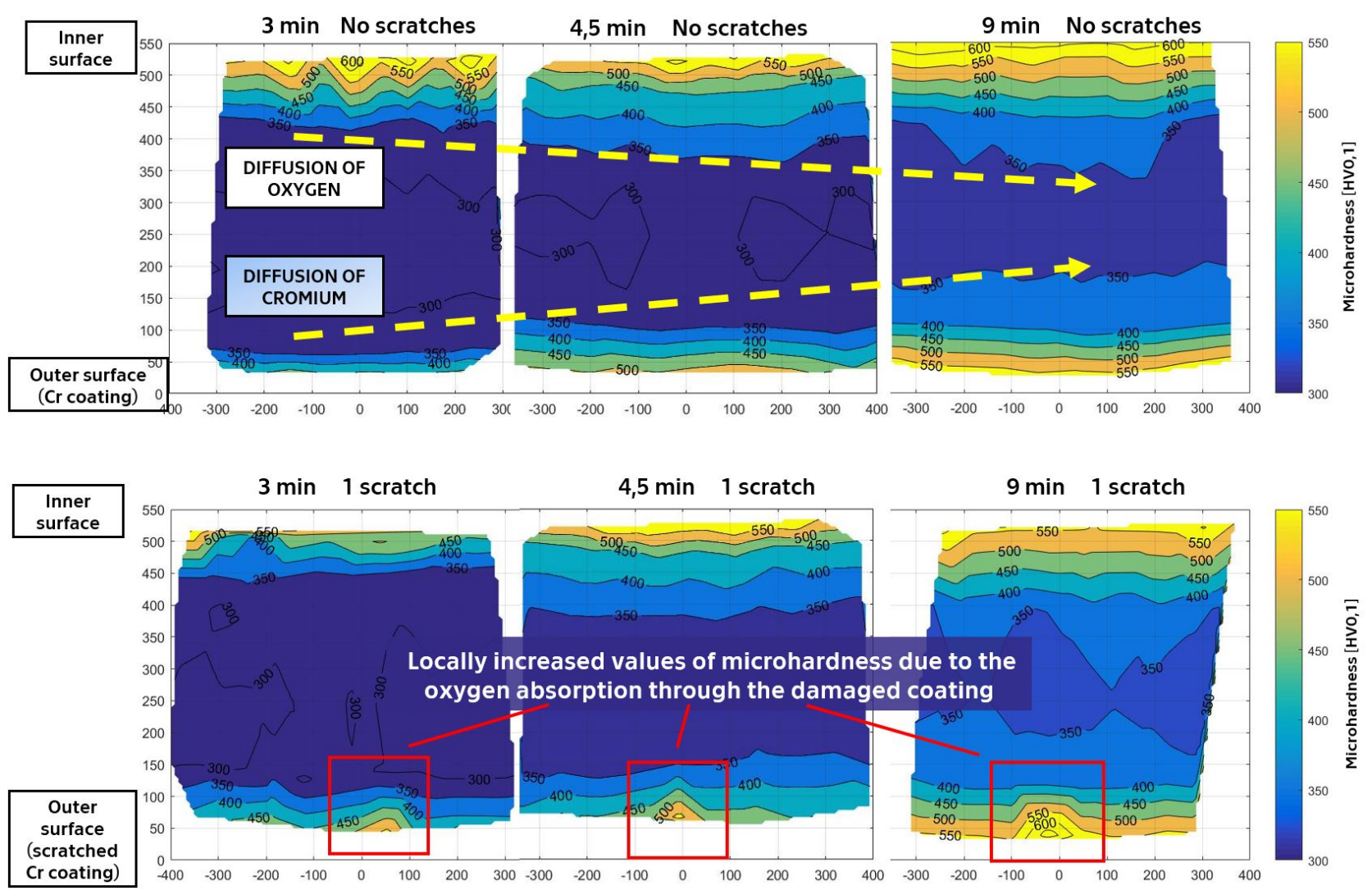

FiguRE 14. Surface plots of microhardness.

Therefore, the suitable methodology remains a subject of further research. Scratches made on the scratch test device allow us to customize the geometry of the scratch. On the other hand, the actual cracking would be more precisely reached by performing burst tests first.

In the Figure 15, the residual ductility in relation with the microhardness values measured in the middle of the cladding wall can be seen. The critical microhardness value for uncoated $\mathrm{Zr}-1 \% \mathrm{Nb}$ (M5) cladding for ductile-brittle transition (DBT) is 300 350 HV0,1 13. Presented results (red and yellow dots) are in accordance with the existing results. Moreover, according to the following studies [1, 14, the Crcoated specimens performing double-sided oxidation at various temperatures (blue dots) feature similar values for DBT, thus the obtained results seem to be relevant.

The impact of scratch on the measured hardness seems to be very local. The reason behind this might be the $\mathrm{Cr}$ diffusing into $\beta-\mathrm{Zr}$ and stabilizing it, which leads to $\mathrm{Cr}$ enriched prior $\beta$ phase. As there is no $\mathrm{Cr}$ in the area of damaged coating, the area below the scratch is not affected by diffusing $\mathrm{Cr}$. The growth of $\alpha-\operatorname{Zr}(\mathrm{O})$ through the scratch is therefore impeded. That would explain the rather local impact of scratches where the $\alpha-\operatorname{Zr}(\mathrm{O})$ grows practically only in a radial direction.

Accordingly, Cr stabilized $\beta$-Zr absorbs diffusing oxygen. The diffusion process of oxygen into $\beta-\mathrm{Zr}$

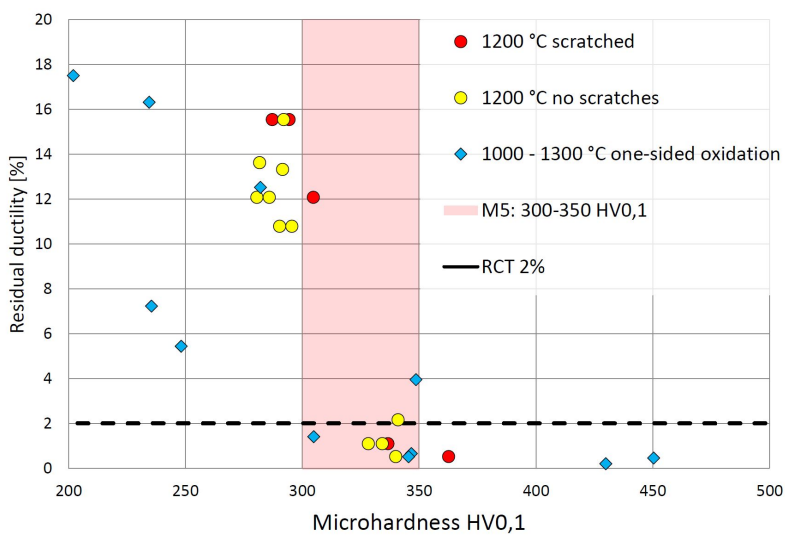

Figure 15. Comparison of obtained results with the ones presented in other studies

might be accelerated due to the concentration of $\mathrm{Cr}$ dissolved. Regarding the diffusion kinetics, Cr seems to dissolve in the cladding metal faster than oxygen thanks to its high diffusion coefficient. Dissolved Cr might cause the accelerated diffusive process of oxygen. Such results would be in accordance with existing knowledge [6, 15]. Nevertheless, the possible (and rather likely present) interaction of diffusing $\mathrm{Cr}$ and oxygen needs to be observed. Currently, the negative interaction among distant scratches can not be excluded. 


\section{Conclusions}

The mechanical properties of the potentially damaged $\mathrm{Cr}$ coating of Zr-based nuclear fuel cladding in post-accident conditions were studied. Cracks of the coating occurring in the first stage of LB- LOCA were simulated by creating scratches using the Scratch Test device. The oxidation through the coating was not observed. It was proved that the coating thickness of $18,6 \mathrm{\mu m}$ is sufficient to prevent the specimens from oxidation for times of high-temperature oxidation of up to 9 minutes. Presented results show the positive impact of Cr coating on the overall mechanical properties after the high-temperature transient. The impact of scratch on the ductile-brittle transition was studied as well. The presence of the scratch did not cause a decrease in residual ductility.

By using the standard methodology, i.e., weight gain, residual ductility, hydrogen pickup, microhardness in the middle of the cladding wall, the $\mathrm{Cr}$ coating features an unequivocally positive impact. A more detailed measurement of microhardness through the whole cladding wall revealed diffusion of $\mathrm{Cr}$ coating into the $\mathrm{Zr}$ substrate. This diffusion process has to be considered and further observation is needed.

\section{ACKNOWLEDGEMENTS}

The authors would like to express gratitude to the whole Zirconium Alloys Team at UJP PRAHA a.s. led by V.Vrtílková for running the experiments and their help with the post-experimental analysis.

\section{REFERENCES}

[1] J. Krejčí, J. Kabátová, F. Manoch, et al. Development and testing of multicomponent fuel cladding with enhanced accidental performance. Nuclear Engineering and Technology 52(3):597 - 609, 2020.

DOI:10.1016/j.net.2019.08.015

[2] OECD/NEA. Nuclear fuel behaviour in loss-of-coolant accident (loca) conditions. state-of-the-art report. NEA No 6846, ISBN 978-92-64-99091-3, Organisation for Economic Co-operation and Development/Nuclear Energy Agency 2009.

[3] N. E. Agency. State-of-the-Art Report on Light Water Reactor Accident-Tolerant Fuels. 2018. DOI:10.1787/9789264308343-en.

[4] J. Krejci, M. Sevecek, L. Cvrcek. Development of chromium and chromium nitride coated cladding for vver reactors. 2017 WRFPM 2017.

[5] K. Daub, R. Van Nieuwenhove, H. Nordin. Investigation of the impact of coatings on corrosion and hydrogen uptake of zircaloy-4. Journal of Nuclear Materials 467:260-270, 2015.

[6] J. Krejci, M. Sevecek, J. Kabátová, et al. Experimental behavior of chromium-based coatings. 2018.
[7] O. Novak, M. Sevecek. Neutronic analysis of the candidate multi-layer cladding materials with enhanced accident tolerance for wwer reactors. Acta Polytechnica CTU Proceedings 14:27, 2018. DOI:10.14311/APP.2018.14.0027.

[8] A. Chalupová, J. Krejci, L. Cvrček, et al. Coated cladding behavior during high-temperature transients. Acta Polytechnica CTU Proceedings 24, 2019. DOI:10.14311/APP.2019.24.0009.

[9] M. Ozawa, T. Takahashi, T. Homma, K. Goto. Behavior of irradiated zircaloy-4 fuel cladding under simulated loca conditions. ASTM Special Technical Publication pp. 279-299, 2000.

[10] L. Lowry, A. Markworth, J. Perrin, M. Landow. Evaluating strength and ductility of irradiated zircaloy, task 5 experimental data final report. Tech. rep., Report NUREG/CR-1729, BMI-2066, 1981.

[11] L. A. Yegorova. Experimental study of embrittlement of $Z r-1 \% \mathrm{Nb}$ VVER cladding under LOCA-relevant conditions. Office of Nuclear Regulatory Research, US Nuclear Regulatory Commission, 2005.

[12] G. Hache, H. Chung. The history of loca embrittlement criteria. Tech. rep., Argonne National Lab., IL (US), 2001.

[13] J.-C. Brachet, V. Vandenberghe-Maillot, L. Portier, et al. Hydrogen content, preoxidation, and cooling scenario effects on post-quench microstructure and mechanical properties of zircaloy- 4 and $\mathrm{m} 5{ }^{\circledR}$ alloys in loca conditions. Journal of ASTM International 5(5):1-28, 2008.

[14] Analysis of Options and Experimental Examination of Fuels for Water Cooled Reactors with Increased Accident Tolerance (ACTOF). No. 1921 in TECDOC Series. INTERNATIONAL ATOMIC ENERGY AGENCY, Vienna, 2020.

[15] W. Xiang, S. Ying. Reaction diffusion in chromium-zircaloy-2 system. Tech. rep., China Nuclear Information Centre, 2001. 